\title{
The heat of formation of chlorine-isocyanate and the relative stability of isoelectronic molecules: An experimental and theoretical study
}

\author{
Yuanyuan $\mathrm{Ji}$ \\ Department of Chemistry and Biochemistry, University of California, Santa Barbara, California 93106 \\ Petia Bobadova-Parvanova \\ Cherry L. Emerson Center for Scientific Computation and Department of Chemistry, Emory University, \\ Atlanta, Georgia 30322 \\ Chris Larson and Peter C. Samartzis \\ Department of Chemistry and Biochemistry, University of California, Santa Barbara, California 93106 \\ Keiji Morokuma \\ Cherry L. Emerson Center for Scientific Computation and Department of Chemistry, Emory University, \\ Atlanta, Georgia 30322 \\ Jim Jr-Min Lin, Tao-Tsung Ching, and Chanchal Chaudhuri \\ Institute of Atomic and Molecular Sciences, Academia Sinica, P.O. Box 23-166, Taipei 106, Taiwan, \\ Republic of China

\begin{abstract}
Shih-Huang Lee
National Synchrotron Radiation Research Center, 101 Hsin-Ann Rd., Science-Based Industrial Park, Hsinchu 30077, Taiwan, Republic of China
\end{abstract} \\ Alec M. Wodtke ${ }^{\text {a) }}$ \\ Department of Chemistry and Biochemistry, University of California, Santa Barbara, California 93106
}

(Received 19 April 2006; accepted 15 May 2006; published online 29 June 2006)

\begin{abstract}
Accurate thermochemical data of small molecules are invaluable to the progress of every aspect of chemistry, especially in the atmosphere, combustion and industry. In this work, photofragmentation translational spectroscopy and 1 st principles electronic structure theory reveal the literature value of the heat of formation of chlorine-isocyanate to be in error by more than $40 \mathrm{kcal} / \mathrm{mol}$. We report a revised experimental value for $D_{0}(\mathrm{Cl}-\mathrm{NCO})=51 \pm 3 \mathrm{kcal} / \mathrm{mol}$ which leads to a $\Delta H_{f}(\mathrm{ClNCO})$ $=8.5 \pm 3 \mathrm{kcal} / \mathrm{mol}$. High level ab initio $(\mathrm{CCSD}(\mathrm{T}))$ electronic structure calculations extrapolated to the complete basis set limit give $D_{0}(\mathrm{Cl}-\mathrm{NCO})=56.3 \mathrm{kcal} / \mathrm{mol}$, in good agreement with experiment . In light of the present results, the destabilization of azides relative to isoelectronic isocyanates has been evaluated empirically for three pairs of related molecules. It is found to be $90-110 \mathrm{kcal} / \mathrm{mol}$, and has been attributed mainly to the weakening of the $\mathrm{N}-\mathrm{NN}$ bond relative to the $\mathrm{N}-\mathrm{CO}$ bond. Electronic structure calculations employing decomposition analysis suggest that, compared to homopolar $\mathrm{N}_{2}$, the ${ }^{+\delta} \mathrm{CO}^{-\delta} \pi$ polarity provides better orbital interaction (charge transfer) and electrostatic attraction and results in a closer encounter and larger stabilization between the fragments and that this is the origin of isoelectronic destabilization of azides relative to the isocyanates. (C) 2006 American Institute of Physics. [DOI: 10.1063/1.2210934]
\end{abstract}

In light of recent experimental ${ }^{1-3}$ and theoretical ${ }^{4}$ work concerning the possibility of producing cyclic- $\mathrm{N}_{3}$ from $\mathrm{X}-\mathrm{N}_{3}$ photolysis, we undertook a study of the collision free photochemistry of the isoelectronic ClNCO molecule to explore conditions where the theoretically-predicted cyclicNCO species might be found. ${ }^{5-7}$ The strategy of the study was to measure high resolution translational energy release distributions of products of ultraviolet (UV) photolysis of the $\mathrm{N}-\mathrm{Cl}$ bond fission reaction (1):

$$
\mathrm{ClNCO}+\mathrm{h} \nu \rightarrow \mathrm{Cl}+\mathrm{NCO} .
$$

\footnotetext{
${ }^{a)}$ Author to whom correspondence should be addressed. Electronic mail: wodtke@chem.ucsb.edu
}

Through knowledge of accurate thermochemistry, the measurement of the translational energy release can be used to derive the internal energy content of the NCO. Formation of the cyclic isomer of NCO would appear as a second lower energy peak in the translational energy release distribution, with an excitation energy corresponding to the cyclization energy of NCO.

A full exposition of the experimental methods used in this work will appear in a future article. For now we mention only that the methods used were nearly identical to those reportedly recently for experiments on $\mathrm{ClN}_{3}{ }^{3}$ Here a molecular beam of $\mathrm{ClNCO}$ seeded in $\mathrm{He}$ was formed in a reactor using $\mathrm{Cl}_{2}$ and $\mathrm{AgNCO}{ }^{8}$ Photolysis was carried out at $193 \mathrm{~nm}$ using an ArF laser. The photo-ionizing radiation from the synchrotron was at a photon-energy of 


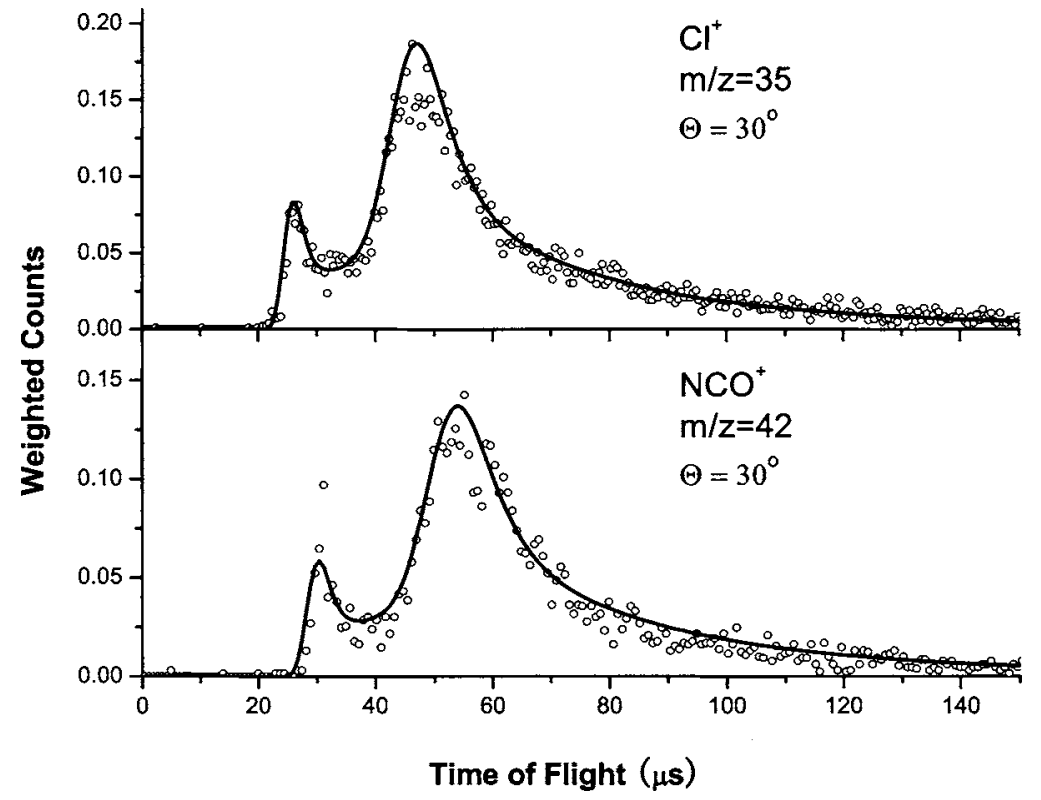

FIG. 1. Representative time-of-flight (TOF) spectra of the major products of the primary collision-free photodissociation of chlorine-isocyanate, $\quad \mathrm{ClNCO} \rightarrow \mathrm{Cl}$ $+\mathrm{NCO}$, at $193 \mathrm{~nm}$. The upper and lower traces show the results for detection of $\mathrm{Cl}^{+}$and $\mathrm{NCO}^{+}$, which result from synchrotron non-dissociative $(h \nu=14.8 \mathrm{eV})$ photoionization of $\mathrm{Cl}$ and $\mathrm{NCO}$, respectively. The products are detected at a laboratory-frame recoil angle of $30^{\circ}$ with respect to the CINCO molecular beam. The open circles represent the data and the solid lines are the forward convolution simulation of the $\mathrm{Cl}+\mathrm{NCO}$ forming channel using the center-of-mass frame translational energy distribution, $P\left(E_{T}\right)$, shown in Fig. 2. These TOF spectra were taken sequentially to ensure nearly identical experimental conditions. The excellent fit to the data of both $\mathrm{Cl}$ and $\mathrm{NCO}$ with a single $P\left(E_{T}\right)$ shows that the two photo-fragments are "momentummatched," unambiguously proving they result from reaction (1) and that NCO does not undergo unimolecular dissociation on the $100 \mu \mathrm{s}$ time-scale of the experiment.

$14.8 \pm 0.2 \mathrm{eV}$, well above the ionization threshold of $\mathrm{Cl}$ and $\mathrm{NCO}$, but still below the dissociative ionization limits of $\mathrm{CINCO}, \mathrm{NCO}, \mathrm{NCl}$, or $\mathrm{CO}$. Figure 1 shows neutral time-offlight (TOF) data obtained with the photofragmentation translational spectroscopy apparatus at the NSRRC in Hsinchu, Taiwan, for one angle of recoil and two values of $\mathrm{m} / \mathrm{z}$ $=35\left(\mathrm{Cl}^{+}\right)$and $42\left(\mathrm{NCO}^{+}\right)$. We also observed extremely weak $m / z=49\left(\mathrm{NCl}^{+}\right)$and $m / z=28\left(\mathrm{CO}^{+}\right)$signals (which suggests that $\mathrm{ClNCO} \rightarrow \mathrm{NCl}+\mathrm{CO}$ is a minor channel) and negligible $m / z=14\left(\mathrm{~N}^{+}\right)$signal. The neutral TOF from the position where ArF laser photolysis is accomplished to the position where vacuum ultraviolet (VUV) photoionization of photoproducts occurs $(10.05 \mathrm{~cm}$ away) is the $x$-axis of Fig. 1 . The open circles in Fig. 1 are the TOF data-ion counts recorded by a Daly-style ion detector at a specific $\mathrm{m} / \mathrm{z}$-value passed by a quadrupole mass filter. The ion counts have been normalized to number of laser shots, laser power, and $\mathrm{CINCO}$ concentration in the molecular beam, as monitored by a residual gas analyzer in the molecular-beam source region. The solid line is the (forward convolution) simulated TOF spectrum obtained using the center-of-mass frame translational energy distribution, $P\left(E_{T}\right)$ of reaction (1), shown in Fig. 2. The good fit to both TOFs by the same $P\left(E_{T}\right)$ indicates that $\mathrm{Cl}$ and $\mathrm{NCO}$ are "momentum-matched" and derive from the same dissociation process of CINCO. It is noteworthy that the $P\left(E_{T}\right)$ predicts the $m / z=42$ TOF of Fig. 1 well even at large values of the TOF where NCO is formed with the low $E_{T}$ and hence high internal energy. This characteristic of the observations indicates that NCO does not dissociate before reaching the ionization region of the apparatus some $100 \mu \mathrm{s}$ after photolysis.

In carrying out the analysis of these experiments, we found that the use of literature thermochemistry for interpretation of $P\left(E_{T}\right)$ of reaction (1) led to puzzling results. Specifically an apparent tendency to produce highly internally excited NCO with a concomitant lack of translational energy release and, more troubling, no evidence of NCO unimolecular decomposition when the molecule was apparently formed above its spin-allowed dissociation limit. The dashed downward-pointing arrows in Fig. 2 show the apparent maximum, $\epsilon_{T}^{\max }$, and minimum, $\epsilon_{T}^{\min }$, translational energy release predicted from published thermochemistry. Observed reaction at a translational energy equal to $\epsilon_{T}^{\max }$ would correspond to formation of $\mathrm{Cl}+\mathrm{NCO}$ with no internal energy in either product. Translational energy less than $\epsilon_{T}^{\min }$ would pro-

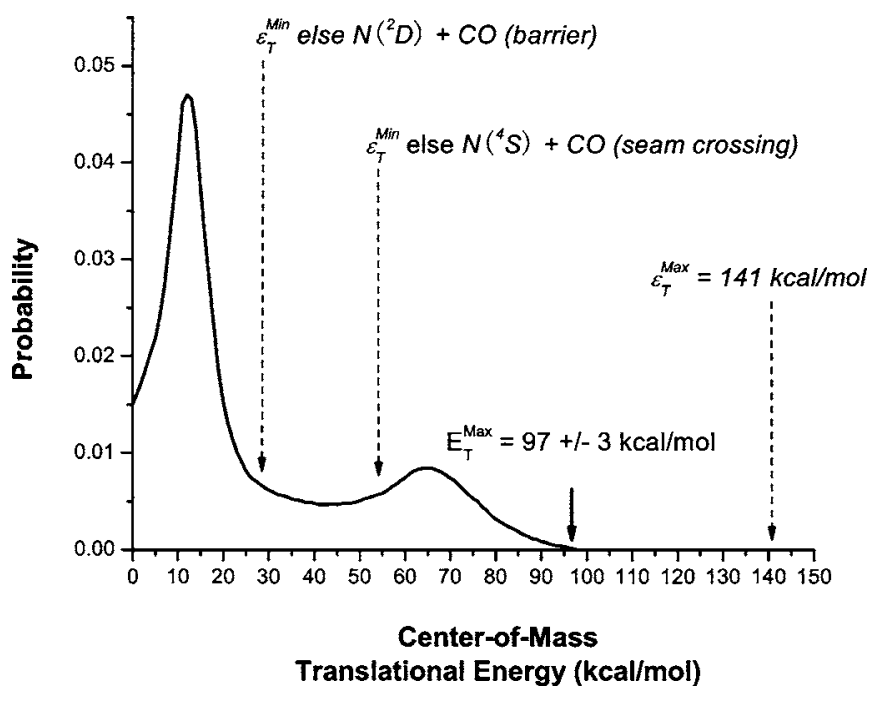

FIG. 2. Center-of-mass translational energy release distribution, $P\left(E_{T}\right)$, for the dominant photodissociation channel of chlorine-isocyanate, $\mathrm{ClNCO}$ $\rightarrow \mathrm{Cl}+\mathrm{NCO}$, at $193 \mathrm{~nm}$. The observed maximum translational energy release, $E_{T}^{\max }=97 \pm 3 \mathrm{kcal} / \mathrm{mol}$, yields an upper limit to the bond energy of $D_{0}(\mathrm{Cl}-\mathrm{NCO})=51 \pm 3 \mathrm{kcal} / \mathrm{mol}$. From known heats of formation for $\mathrm{Cl}$ (Ref. 9) and NCO (Ref. 10) $\Delta H_{f}(\mathrm{ClNCO})$ is found to be $8.5 \pm 3 \mathrm{kcal} / \mathrm{mol}$. These results are in good agreement with the ab-initio electronic structure calculations presented in Table I. The only previously available value, $\Delta H_{f}(\mathrm{ClNCO})>52.9 \mathrm{kcal} / \mathrm{mol}$ (Ref. 8), implies a $\epsilon_{T}^{\max }>141 \mathrm{kcal} / \mathrm{mol}$, and would mean that at translational energies below $27 \mathrm{kcal} / \mathrm{mol}$, NCO is formed with sufficient internal energy for spin-allowed dissociation to $\mathrm{N}\left({ }^{2} \mathrm{D}\right)+\mathrm{CO}$ (Ref. 6). A doublet/quartet curve crossing has recently been identified (Ref. 7) that, again using the previous thermochemistry (Ref. 8), implies spin forbidden unimolecular dissociation of $\mathrm{NCO}$ at translational energies below $54 \mathrm{kcal} / \mathrm{mol}$. No evidence of $\mathrm{NCO}$ dissociation is observed in this work. 
TABLE I. Results of electronic structure theory. $\operatorname{CCSD}(\mathrm{T})$ calculations of $\mathrm{Cl}-\mathrm{NCO}$ bond energies using different basis sets with increasing level of sophistication. Data are corrected for basis set superposition error (BSSE) and zero-point vibrational energy (ZPE). The complete basis set limit (CBS) is calculated after focal point analysis of the cc- $p \mathrm{VxZ}$ data (see text). All energies are in $\mathrm{kcal} / \mathrm{mol}$.

\begin{tabular}{lcccc}
\hline \hline Basis set & $D_{0}(\mathrm{Cl}-\mathrm{NCO})^{\text {uncorr }}$ & BSSE & ZPE & $D_{0}(\mathrm{Cl}-\mathrm{NCO})$ \\
\hline cc-pVTZ & 52.64 & -2.20 & -1.83 & 48.61 \\
aug-cc-pVTZ & 54.26 & -2.17 & -1.82 & 50.27 \\
cc-pVQZ & 55.59 & -0.89 & -1.85 & 52.84 \\
cc-pV5Z & 57.11 & -0.44 & $-1.85^{\mathrm{a}}$ & 54.82 \\
CBS limit & 58.16 & 0 & $-1.85^{\mathrm{a}}$ & 56.31 \\
\hline \hline
\end{tabular}

${ }^{\mathrm{a}}$ The cc-pVQZ value is used.

duce NCO with enough internal energy to dissociate over the barrier to spin-allowed products, $\mathrm{N}\left({ }^{2} \mathrm{D}\right)+\mathrm{CO}$. The value of $\epsilon_{T}^{\min }$ which would access a theoretically predicted seam crossing to spin-forbidden dissociation is also shown.

In light of these puzzling implications, a review of the literature thermochemistry was undertaken. The presently recommended literature values of the relevant heats of formation are: for CINCO $\left(\Delta H_{f}>52.9 \mathrm{kcal} / \mathrm{mol}\right){ }^{8}$ for $\mathrm{Cl}\left(\Delta H_{f}=28.992 \mathrm{kcal} / \mathrm{mol}\right)^{9}$ and for $\mathrm{NCO}\left(\Delta H_{f}\right.$ $=30.5 \mathrm{kcal} / \mathrm{mol}){ }^{10}$ These values suggest a dissociation energy, $D_{0}(\mathrm{Cl}-\mathrm{NCO})$ of less than $6 \mathrm{kcal} / \mathrm{mol}$. Such a low bond energy is suspect on its face. Consider that $\mathrm{ClN}_{3}$ exhibits a dissociation energy of $D_{0}\left(\mathrm{Cl}-\mathrm{N}_{3}\right)=49 \mathrm{kcal} / \mathrm{mol}^{1}$ and that in a chemically similar pair, $D_{0}(\mathrm{H}-\mathrm{NCO})$ is about $15 \%$ larger than $D_{0}\left(\mathrm{H}-\mathrm{N}_{3}\right)$. Thus one might reasonably postulate a value of $D_{0}(\mathrm{Cl}-\mathrm{NCO})$ closer to $55 \mathrm{kcal} / \mathrm{mol}$ which is $12 \%$ larger than $D_{0}\left(\mathrm{Cl}-\mathrm{N}_{3}\right)$. It is also clear that any error in the thermochemistry must involve the $\mathrm{CINCO}$ heat of formation as the heats of formation of $\mathrm{NCO}$ and $\mathrm{Cl}$ appear secure, having been reproduced by multiple high-level experiments and confirmed by accurate electronic structure calculations.

In light of these internal inconsistencies, we are led to revise the literature value of $\Delta H_{f}(\mathrm{ClNCO})$ by a simple analysis of the $P\left(E_{T}\right)$ of Fig. 2. Here, we assume that the maximum observed release of translational energy, $\epsilon_{T}^{\max }$, corresponds to formation of $\mathrm{Cl}$ and $\mathrm{NCO}$ with no internal energy. This assumption yields an upper bound to the value of $D_{0}(\mathrm{Cl}-\mathrm{NCO})=51 \pm 3 \mathrm{kcal} / \mathrm{mol}$ and $\Delta H_{f}(\mathrm{ClNCO})$ $=8 \pm 3 \mathrm{kcal} / \mathrm{mol}$.

The large disagreement with previous work, led us to seek confirmation by independent means. Thus, $a b$ initio electronic structure theory was used to independently derive $D_{0}(\mathrm{Cl}-\mathrm{NCO})$. Table I shows the results of these calculations, carried out using conventional coupled cluster $\operatorname{CCSD}(\mathrm{T})^{11}$ (coupled cluster singles and doubles with perturbative triples) treatment of electronic correlation and the (aug)-cc$p \mathrm{VxZ}$ families of basis sets ${ }^{12}$ with increasing levels of sophistication $[x=3(\mathrm{~T}), 4(\mathrm{Q})$, and 5]. The geometries of CINCO and NCO were optimized at $\operatorname{CCSD}(\mathrm{T}) / \mathrm{cc}-p \mathrm{VTZ}$ level of theory. Values at higher basis sets were obtained as a single-point calculation on the optimized cc- $p$ VTZ geometry. The $D_{0}(\mathrm{Cl}-\mathrm{NCO})$ energies were corrected for basis set superposition error (BSSE) ${ }^{13}$ and zero-point vibrational energy (ZPE). As could be expected, BSSE decreases with increas- ing basis set quality and becomes less than $0.8 \%$ for the highest quality basis sets used. All above calculations were performed using GAUSSIAN 03 program package. ${ }^{14}$

To evaluate the complete basis set limit (CBS) we performed focal point analysis ${ }^{15}$ of the cc- $p \mathrm{VxZ}$ data. The Hartree-Fock energies were extrapolated using $x=3$, 4, and 5 and the exponential form of Feller et al. ${ }^{16}$ The correlation energies were extrapolated using $x=4$ and 5 and the integrated Schwartz expression. ${ }^{17}$ The results are shown in the last row of Table I. As can be seen, the 1st principles electronic structure theory suggests a $D_{o}(\mathrm{Cl}-\mathrm{NCO})$ value of $56.3 \mathrm{kcal} / \mathrm{mol}$, in good agreement with the new experimental results of $51 \pm 3 \mathrm{kcal} / \mathrm{mol}$.

The revised heat of formation and atomization energy allow comparison between six related molecules, revealing the magnitude of destabilization of azide with respect to the isoelectronic isocyanates, as shown in Fig. 3. At first we will examine hydrides in Figs. 3(a) and 3(b). The atomization energy of $\mathrm{HN}_{3}$ to the ground state atoms: $\mathrm{H}\left({ }^{2} \mathrm{~S}\right)+3 \mathrm{~N}\left({ }^{4} \mathrm{~S}\right)$ is smaller by $109 \mathrm{kcal} / \mathrm{mol}$ than the atomization energy of $\mathrm{HNCO}$ to the ground state atoms: $\mathrm{H}\left({ }^{2} \mathrm{~S}\right)+\mathrm{N}\left({ }^{4} \mathrm{~S}\right)+\mathrm{C}\left({ }^{3} \mathrm{P}\right)$ $+\mathrm{O}\left({ }^{3} \mathrm{P}\right)$. One might be tempted to consider this difference the fundamental azide versus isocyanate destabilization energy. However, since the $\mathrm{CO}$ bond energy $(257 \mathrm{kcal} / \mathrm{mol})$ is $31 \mathrm{kcal} / \mathrm{mol}$ larger than the $\mathrm{N}_{2}$ bond energy $(226 \mathrm{kcal} / \mathrm{mol})$, the difference in dissociation energy between $\mathrm{HN}_{3} \rightarrow \mathrm{HN}$ $+\mathrm{N}_{2} \quad(50 \mathrm{kcal} / \mathrm{mol})$ and that of $\mathrm{HNCO} \rightarrow \mathrm{HN}+\mathrm{CO}$ $(128 \mathrm{kcal} / \mathrm{mol})$ is a better measure of this so-called "azide destabilization." An alternative analysis through HNXY $\rightarrow \mathrm{H}+\mathrm{NXY} \rightarrow \mathrm{H}+\mathrm{N}+\mathrm{XY}$ (where $\mathrm{XY}$ is $\mathrm{N}_{2}$ or $\mathrm{CO}$ ) route shows that $\mathrm{H}-\mathrm{NNN}$ bond is $22 \mathrm{kcal} / \mathrm{mol}$ weaker than the $\mathrm{H}-\mathrm{NCO}$ bond, and the $\mathrm{N}-\mathrm{NN}$ bond is $56 \mathrm{kcal} / \mathrm{mol}$ weaker than the $\mathrm{N}-\mathrm{CO}$ bond. One clearly sees that the azide destabilization mainly originates from the weakness of the $\mathrm{N}-\mathrm{NN}$ bond relative to the $\mathrm{N}-\mathrm{CO}$ bond.

The situation is similar for the chloride, $\mathrm{ClN}_{3}$ versus CINCO, as shown in Figs. 3(c) and 3(d). The dissociation energy of $\mathrm{ClN}_{3} \rightarrow \mathrm{ClN}+\mathrm{N}_{2}(7 \mathrm{kcal} / \mathrm{mol})$ is $58 \mathrm{kcal} / \mathrm{mol}$ smaller than that of $\mathrm{CINCO} \rightarrow \mathrm{ClN}+\mathrm{CO}(65 \mathrm{kcal} / \mathrm{mol})$. The weakness of the $\mathrm{ClN}-\mathrm{NN}$ bond relative to the $\mathrm{ClN}-\mathrm{CO}$ bond, "the azide destabilization," is recognized here as well. An alternative analysis through $\mathrm{ClNXY} \rightarrow \mathrm{Cl}+\mathrm{NXY} \rightarrow \mathrm{Cl}$ $+\mathrm{N}+\mathrm{XY}$ (where $\mathrm{XY}$ is $\mathrm{N}_{2}$ or $\mathrm{CO}$ ) route shows that $\mathrm{Cl}-\mathrm{NNN}$ bond is only $2 \mathrm{kcal} / \mathrm{mol}$ weaker than the $\mathrm{Cl}-\mathrm{NCO}$ bond and most of the azide destabilization is due to the fact that the $\mathrm{N}-\mathrm{NN}$ bond is $56 \mathrm{kcal} / \mathrm{mol}$ weaker than the $\mathrm{N}-\mathrm{CO}$ bond, as discussed above.

To understand the origin of the "azide destabilization," the $78 \mathrm{kcal} / \mathrm{mol}$ difference in dissociation energy between $\mathrm{HN}-\mathrm{N}_{2}(50 \mathrm{kcal} / \mathrm{mol})$ and $\mathrm{HN}-\mathrm{CO}(128 \mathrm{kcal} / \mathrm{mol})$ and the $58 \mathrm{kcal} / \mathrm{mol}$ difference between $\mathrm{ClN}-\mathrm{N}_{2}(7 \mathrm{kcal} / \mathrm{mol})$ and $\mathrm{ClN}-\mathrm{CO}(65 \mathrm{kcal} / \mathrm{mol})$, we performed energy decomposition analysis ${ }^{18}$ at the RHF/cc- $p$ VTZ level using the GAMESS program package. ${ }^{19}$ In this analysis the bonding stabilization energy (negative of the bond energy) is divided into three terms: electrostatic interaction, ES, exchange repulsion, EX, and orbital interaction, ORB. For detailed definition of these terms, the readers are referred to the original paper. ${ }^{18}$ The electrostatic interaction, ES, represents the purely classical 


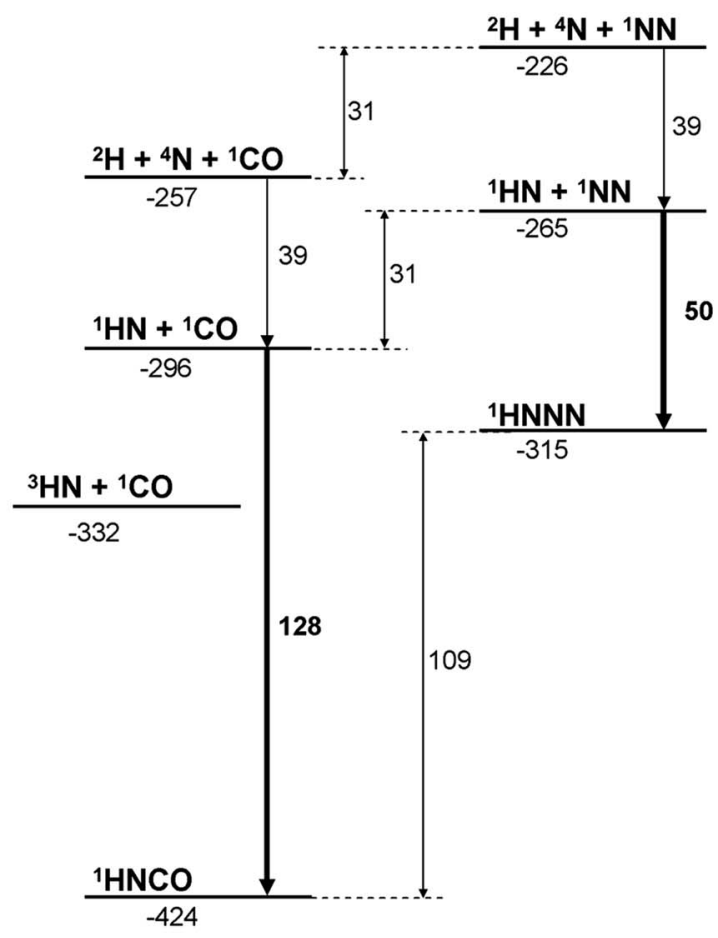

A

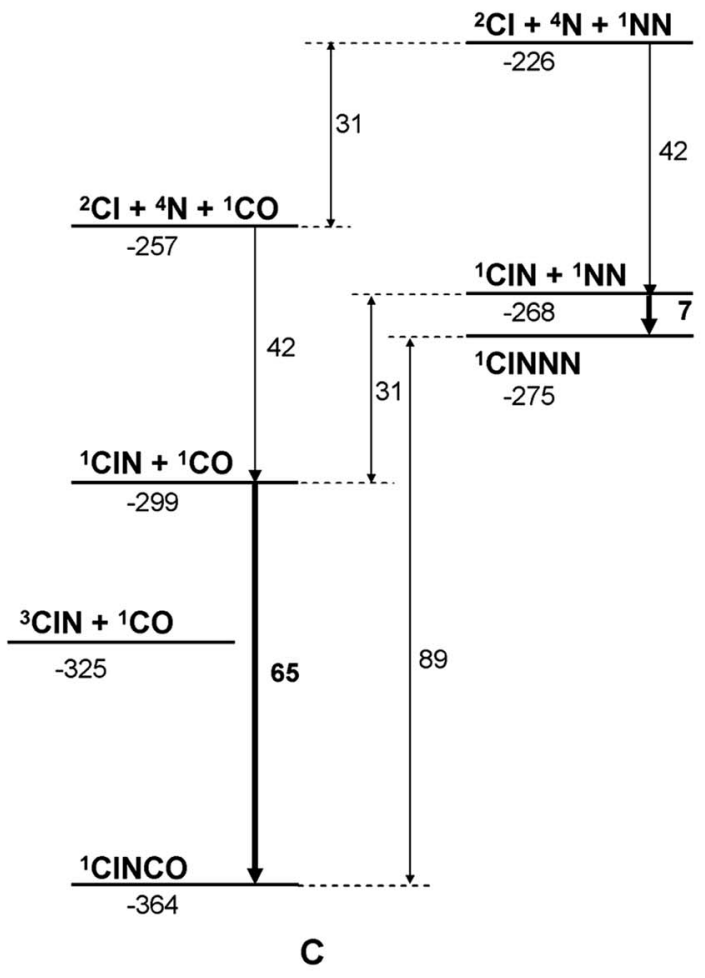

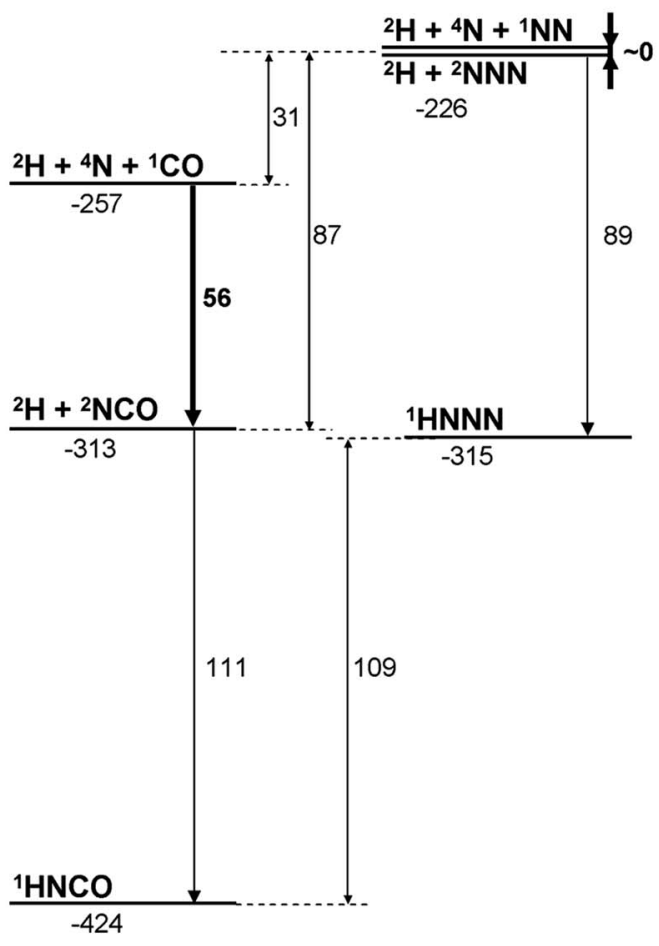

B

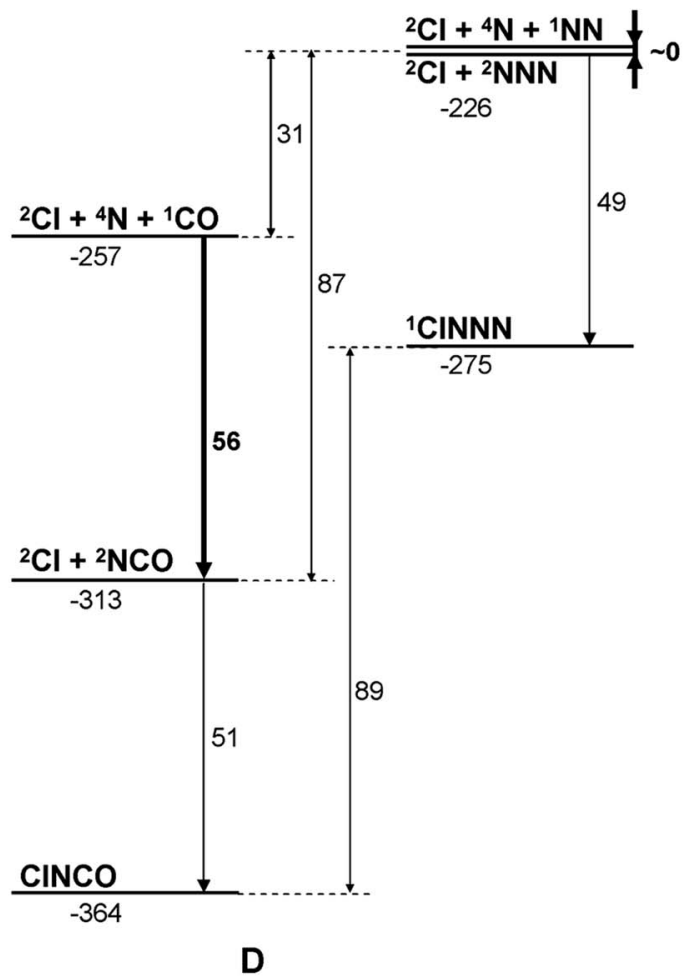

FIG. 3. Experimental energetics (in $\mathrm{kcal} / \mathrm{mol}$ ) of formation of $\mathrm{HNXY}\left(\mathrm{XY}=\mathrm{CO}, \mathrm{N}_{2}\right)$ from a) $\mathrm{HN}$ and $\mathrm{XY}$ and b) $\mathrm{H}$ and $\mathrm{NXY}$; and $\mathrm{ClNXY}\left(\mathrm{XY}=\mathrm{CO}, \mathrm{N}_{2}\right)$ from c) $\mathrm{ClN}$ and $\mathrm{XY}$ and d) $\mathrm{Cl}$ and $\mathrm{NXY}$.

interaction between the charge distributions obtained from the wavefunctions of the individual fragments, HN and XY. The exchange repulsion, EX, is the repulsion energy originating from the requirement that the total wave function made of the wave functions of individual fragments has to satisfy the Pauli principle. The orbital interaction, ORB, is everything else and due to the overall reorganization of orbitals including charge transfer and polarization. 
The results of the energy decomposition analysis point out that the bonding between $\mathrm{HN}$ and $\mathrm{CO}$ at the $\mathrm{HNCO}$ equilibrium geometry has $261 \mathrm{kcal} / \mathrm{mol}$ larger exchange repulsion, $116 \mathrm{kcal} / \mathrm{mol}$ more attractive electrostatic interaction and $223 \mathrm{kcal} / \mathrm{mol}$ more attractive orbital terms than the bonding between $\mathrm{HN}$ and $\mathrm{N}_{2}$ at the $\mathrm{HN}_{3}$ equilibrium geometry. The larger values of all the attractive as well as repulsive components for $\mathrm{HN}-\mathrm{CO}$ indicate that this interaction is "stronger" than the $\mathrm{HN}-\mathrm{NN}$ interaction. This is reflected in the shorter $\mathrm{N}-\mathrm{CO}$ distance in $\mathrm{HNCO}$ than the $\mathrm{N}-\mathrm{NN}$ distance in $\mathrm{HN}_{3}$. One recognizes that $\triangle \mathrm{ORB}$ is more dominant than $\Delta \mathrm{ES}$ in $\mathrm{HN}-\mathrm{CO}$ versus $\mathrm{HN}-\mathrm{NN}$ difference. The $\pi$ electrons in $\mathrm{CO}$ are polarized as ${ }^{+\delta} \mathrm{C}-\mathrm{O}^{-\delta}$ and create a situation where it is more favorable to make a dative bond by charge transfer from the filled sp lone pair orbital of $\operatorname{HN}\left({ }^{1} \Delta\right)$ to the in-plane $\pi$ orbital of CO in the bent H-N-CO configuration, while $\mathrm{N}_{2}$ is homopolar and is less likely to form such a dative bond; this must be reflected in the more negative (attractive) ORB term for $\mathrm{HN}-\mathrm{CO}$ compared to $\mathrm{HN}-\mathrm{NN}$, hence in a large negative $\triangle \mathrm{ORB}$. With more attractive orbital interaction, the $\mathrm{HN}-\mathrm{CO}$ distance will be smaller with a larger bond energy and all larger energy components than its $\mathrm{HN}-\mathrm{NN}$ counterparts.

The analysis shows a similar picture for the $58 \mathrm{kcal} / \mathrm{mol}$ difference between $\mathrm{ClN}-\mathrm{N}_{2}(7 \mathrm{kcal} / \mathrm{mol})$ and $\mathrm{ClN}-\mathrm{CO}$ $(65 \mathrm{kcal} / \mathrm{mol})$. The bonding between $\mathrm{ClN}$ and $\mathrm{CO}$ at the ClNCO equilibrium geometry has $131 \mathrm{kcal} / \mathrm{mol}$ larger exchange repulsion, $58 \mathrm{kcal} / \mathrm{mol}$ more attractive electrostatic interaction and $137 \mathrm{kcal} / \mathrm{mol}$ more attractive orbital terms than the bonding between $\mathrm{ClN}$ and $\mathrm{N}_{2}$ at the $\mathrm{ClN}_{3}$ equilibrium geometry. Again, the interaction is "stronger" in $\mathrm{ClN}-\mathrm{CO}$ than in $\mathrm{ClN}-\mathrm{NN}$.

Finally, we comment on a possible problem with the previous derivation of $\Delta H_{\mathrm{f}}(\mathrm{ClNCO})$. That work relied on an argument that 248-nm photolysis of CINCO produced large amounts of $\mathrm{N}\left({ }^{2} \mathrm{D}\right)$. The $\mathrm{N}\left({ }^{2} \mathrm{D}\right)$ was detected indirectly by observation of fluorescence emission resulting from the reactions:

$$
\begin{aligned}
& \mathrm{N}\left({ }^{2} \mathrm{D}\right)+\mathrm{ClNCO} \rightarrow \mathrm{NCl}+\mathrm{NCO}\left(\mathrm{A}^{2} \Sigma\right) \quad \text { and } \\
& \mathrm{N}\left({ }^{2} \mathrm{D}\right)+\mathrm{N}_{2} \mathrm{O} \rightarrow \mathrm{N}_{2}+\mathrm{NO}\left(\mathrm{B}^{2} \Pi\right) .
\end{aligned}
$$

By assuming that the $\mathrm{N}\left({ }^{2} \mathrm{D}\right)$ came from single-photon absorption of ClNCO, a lower limit to $\Delta H_{f}(\mathrm{ClNCO})$ could be extracted. Our results from the NSRRC show no evidence of one photon photochemistry leading to $\mathrm{N}\left({ }^{2} \mathrm{D}\right)$ even at the much higher available energy provided by a 193-nm photon. We presume that the previous work, ${ }^{8}$ carried out at 50 $100 \mathrm{~mJ} / \mathrm{cm}^{2}$ may have been influenced by multiphoton photochemistry.

Based on the thermochemistry derived in this work, we can assign the faster component of the $P\left(E_{T}\right)$ in Fig. 2 to production of $\mathrm{Cl}+\mathrm{NCO}(\mathrm{X})$. The assignment of the slower, high internal energy, component is still an unsolved problem. Several NCO electronic states, including cyclic-NCO, have energetics that can explain this peak. Therefore, the results of this work cannot definitely prove or disprove the possibility of cyclic-NCO formation in ClNCO photolysis at $193 \mathrm{~nm}$. Further experimental and theoretical work will be needed to clarify this point.

A.M.W. acknowledges support from USA AFOSR Grant No. FA9550-04-1-0057. K.M. acknowledges support from USA AFOSR Grants No. FA9550-04-1-0080 and FA955004-1-0321, as well as a computer-time grant under the DoD High Performance Computing Program 1. We acknowledge the Academia Sinica for use of the chemical dynamics end station and the National Synchrotron Radiation Research Center for providing beam time.

${ }^{1}$ N. Hansen and A. M. Wodtke, J. Phys. Chem. A 107, 10608 (2003).
${ }^{2}$ N. Hansen, A. M. Wodtke, A. V. Komissarov, and M. C. Heaven, Chem.
Phys. Lett. 368, 568 (2003); N. Hansen, A. M. Wodtke, A. V. Komissa-
rov, K. Morokuma, and M. C. Heaven, J. Chem. Phys. 118, 10485
(2003); A. M. Wodtke, N. Hansen, J. C. Robinson, N. E. Sveum, S. J.
Goncher, and D. M. Neumark, Chem. Phys. Lett. 391, 334 (2004); N.
Hansen, A. M. Wodtke, S. J. Goncher, J. C. Robinson, N. E. Sveum, and D. M. Neumark, J. Chem. Phys. 123, 10430 (2005).

${ }^{3}$ P. C. Samartzis, J. J. Lin, T. T. Ching, C. Chaudhuri, Y. T. Lee, S. H. Lee, and A. M. Wodtke, J. Chem. Phys. 123, 051101 (2005).

${ }^{4}$ P. Zhang, K. Morokuma, and A. M. Wodtke, J. Chem. Phys. 122, 014106 (2005); D. Babikov, P. Zhang, and K. Morokuma, J. Chem. Phys. 121, 6743 (2004); D. Babikov, B. Kendrick, P. Zhang, and K. Morokuma, J. Chem. Phys. 122, 044315 (2005).

${ }^{5}$ A. M. Mebel, A. Luna, M. C. Lin, and K. Morokuma, J. Chem. Phys. 105, 6439 (1996); S. Andersson, N. Markovic, and G. Nyman, Phys. Chem. Chem. Phys. 2, 613 (2000); M. Simonson, N. Markovic, S. Nordholm, and B. J. Persson, Chem. Phys. 200, 141 (1995).

${ }^{6}$ B. J. Persson, B. O. Roos, and M. Simonson, Chem. Phys. Lett. 236, 532 (1995); B. J. Persson, B. O. Roos, and M. Simonson, Chem. Phys. Lett. 234, 382 (1995).

${ }^{7}$ O. Yazidi, H. Gritli, and G. Chambaud, Mol. Phys. 103, 3321 (2005).

${ }^{8}$ D. D. Bell and R. D. Coombe, J. Chem. Phys. 82, 1317 (1985).

${ }^{9}$ J. D. Cox, D. D. Wagman, and V. A. Medvedev, CODATA Key Values for Thermodynamics (Hemisphere, NY, 1984).

${ }^{10}$ M. S. Schuurman, S. R. Muir, W. D. Allen, and H. F. Schaefer, J. Chem. Phys. 120, 11586 (2004); M. Zyrianov, T. DrozGeorget, A. Sanov, and H. Reisler, J. Chem. Phys. 105, 8111 (1996); D. R. Cyr, R. E. Continetti, R. B. Metz, D. L. Osborn, and D. M. Neumark, J. Chem. Phys. 97, 4937 (1992).

${ }^{11}$ J. A. Pople, M. Head-Gordon, and K. Raghavachari, J. Chem. Phys. 87, 5968 (1987).

${ }^{12}$ T. H. Dunning, J. Chem. Phys. 90, 1007 (1989); R. A. Kendall, T. H. Dunning, and R. J. Harrison, J. Chem. Phys. 96, 6796 (1992); D. E. Woon and T. H. Dunning, J. Chem. Phys. 103, 4572 (1995); A. K. Wilson, T. v. Mourik, and T. H. Dunning, J. Mol. Struct.: THEOCHEM 388, 339 (1996).

${ }^{13}$ S. Simon, M. Duran, and J. J. Dannenberg, J. Chem. Phys. 105, 11024 (1996); S. F. Boys and F. Bernardi, Mol. Phys. 19, 553 (1970).

${ }^{14}$ M. J. Frisch, G. W. Trucks, H. B. Schlegel, et al., GAUSSIAN 03 Revision C.02, Gaussian, Inc., Wallingford, CT 2004.

${ }^{15}$ J. P. Kenny, W. D. Allen, and H. F. Schaefer, J. Chem. Phys. 118, 7353 (2003); A. G. Csaszar, W. D. Allen, and H. F. Schaefer, J. Chem. Phys. 108, 9751 (1998).

${ }^{16}$ D. Feller, J. Chem. Phys. 96, 6104 (1992); D. Feller, J. Chem. Phys. 98, 7059 (1993).

${ }^{17}$ T. Helgaker, W. Klopper, H. Koch, and J. Noga, J. Chem. Phys. 106, 9639 (1997)

${ }^{18}$ K. Kitaura, S. Sakaki, and K. Morokuma, Inorg. Chem. 20, 2292 (1981); K. Morokuma and K. Kitaura, Chemical Applications of Atomic and Molecular Electrostatic Potentials. (Plenum, New York, 1981); G. Frenking and N. Frohlich, Chemical Reviews 100, 717 (2000).

${ }^{19}$ M. W. Schmidt, K. K. Baldridge, J. A. Boatz et al., J. Comput. Chem. 14, 1347 (1993); M. S. Gordon and M. W. Schmidt, Theory and Applications of Computational Chemistry, the first forty years (Elsevier, Amsterdam, 2005). 